\title{
The Comparison of Infertility Stress and Perceived Social Support in Infertile Women and Spouses of Infertile Men
}

\author{
Leila Amini ${ }^{1}$, Behzad Ghorbani ${ }^{2}$, Bahare Afshar $^{3}$
}

\begin{abstract}
Background \& Aims: Infertility is a stressful condition, which could adversely affect the mental health of couples. Although the diagnosis and treatment fertility may be a frustrating crisis affecting both spouses and causing mental distress, a sense of loneliness, disappointment, and lack of control, it seems that these issues are more apparent in women than men since the physical and mental burden of infertility and the consequences of the possible failure mostly falls on women. Women (especially in eastern communities and Iranian women) live in a culture in which having a child and fertility are revered more than other communities. Even when a woman is fertile and has an infertile spouse, infertility stress is experienced similarly since regardless of the cause of infertility, the outcome is eventually is childlessness. The social stigmas experienced by infertile women become more intense when they do not enjoy familial support, causing depression in these women. Therefore, the social support of these individuals could play a key role in their adaptation process to the issue of infertility. In Iran, several studies have been focused on the quality of life and psychological issues of infertile individuals, while most of these studies have investigated the psychological issues of infertile women without much regard for the spouses of infertile men. The present study aimed to compare infertility stress and perceived social support in infertile women and the spouses of the infertile men referring to Akbar Abadi Teaching Hospital in Tehran, Iran. Materials \& Methods: This cross-sectional study was conducted on 164 infertile women and 93 spouses of infertile men referring to the infertility clinic of Akbar Abadi hospital in Tehran during 2015-2016. After obtaining the required permit from Iran University of Medical Sciences by the researcher and co-researcher, they visited the clinic on working days for sampling. After providing the necessary explanations to the hospital authorities and conforming to ethical principles (e.g., obtaining written consent), continuous sampling was performed until the completion of the sample size. The inclusion criteria were the Iranian nationality of the couples, infertility in only one spouse, willingness to participate in the study, absence of chronic physical diseases or known mental disorders, and no consumption of the medications affecting the nervous system by the couples. The subjects were allowed to withdraw from the study at any stages. Data were collected using a demographic questionnaire, Newton infertility stress inventory, and the functional social support questionnaire, which were completed in a self-report manner or with the help of the researcher, enquiring the subjects, and review of their medical records. Data analysis was performed in SPSS version 16 using descriptive and inferential statistics, including Chi-square and independent $\mathrm{t}$-test at the significance level of $\mathrm{P}<0.05$.

Results: No significant differences were observed between the two study groups in terms of age (infertile women: $31.24 \pm 5.68$ years; spouses of infertile men: $30.79 \pm 5.19$ years), duration of marriage (infertile women: $7.29 \pm 4.81$ years; spouses of infertile men: $7.54 \pm 4.13$ years), duration of infertility (infertile women: $4.52 \pm 4.01$ years; spouses of infertile men: $4.66 \pm 3.45$ years), education level, occupation status, and economic status. In addition, $63.6 \%$ of the infertile women and $77.3 \%$ of the spouses of infertile men had primary infertility, while no significant difference was observed between the groups in this regard. No significant differences were denoted between the groups in terms of the scores of the subscales of infertility stress, including social concerns, sexual concerns, communicational concerns, and concerns regarding the lifestyle without a child, with the exception of the subscale of the need for parenthood $(\mathrm{P}=0.038)$. In addition, the total score of infertility stress had no significant difference between the study groups $(\mathrm{P}=0.043)$. The comparison of the mean perceived social support in the infertile women and spouses of infertile men indicated no significant difference in this regard.
\end{abstract}

\footnotetext{
1. Associate Professor, Nursing Care Research Center (NCRC), School of Nursing and Midwifery, Iran University of Medical Sciences, Tehran, Iran

2. Assistant Professor, Reproductive Biotechnology Research Center, ACECR Avicenna Research Institute, Shahid Beheshti University, Tehran, Iran

3. MS Student of Midwifery Counseling, Student Research Committee, School of Nursing and Midwifery, Iran University of Medical Sciences, Tehran, Iran (Corresponding author) Tel: $09128701574 \quad$ Email: bahar.afshar1372m@gmail.com
} 
Conclusion: Although it seems that regardless of the male or female cause of infertility, women experience stress in case of infertility, the overall stress and stress induced by the need for parenthood were higher in the infertile women compared to the spouses of the infertile men. According to the results, the spouses of the infertile men were as stressed as the infertile women in many subscales of infertility. This could be due to the fact that even when the male gender is the cause of infertility, diagnostic and therapeutic procedures are often imposed on women, which increases their concerns compared to their spouses. In the face of infertility stress, women react through anxiety, stress, depression, and grief. One of the major causes of such stress in these women is the fear of divorce and loss of the ability of motherhood. Since pregnancy and the motherhood role are exclusive to women, social expectations are higher in the case of women compared to men, and the fear of the stigma of infertility is more severe in women. It could be stated that due to cultural components and the pre-defined social expectations, the foremost expectation and predicted role for married men and women is to have a child, and lack thereof is frowned upon in the Iranian culture. This shows that in the Iranian culture, the inability to have a child is synonymous with the absence of a fruitful life. Although social support could diminish the stress of infertile individuals, they may still feel the emptiness of their childless life in private, which in turn adversely affects marital relations. Furthermore, it seems that having a child is more important to women than men, and men are able to cope with a childless life more easily than women. Regardless of the cause of infertility, the findings of this study indicated that social support in both the infertile women and spouses of infertile men was similar.

\section{Keywords: Infertility, Social Support, Stress, Depression, Anxiety}

\section{Conflict of Interest: No}

How to Cite: Amini L, Ghorbani B, Afshar B. The Comparison of Infertility Stress and Perceived Social Support in Infertile Women and Spouses of Infertile Men. Iran Journal of Nursing. 2020; 32(122):80-90.

Received: 19 Nov 2019

Accepted: 15 Feb 2020 


\title{
مقايسه استر س نابارورى و حمايت اجتماعى درك شده زنان نابارور و همسران مردان
}

\section{نابارور}

\author{
ليلا امينى '، بهزاد قربانى '، بهاره افشار؟
}

جكS:

زمينه و هدف: نابارورى به يكى موقعيت اسـترس آور بوده كه مىتواند سـلامت روانى زوجين را تحت تأثير قرار دهد. هدف از اين مطالعه مقايســه استرس نابارورى و حمايت اجتماعى درى شده در زنان نابارور و همسران مردان نابارورمراجعه كننده به مركز آموزشى درمانى شهيد اكبر آبادى تهران روش برر سى: اين مطالعه مقطعى برروى عَازن نابارور بهو نفر از همسـران مردان نابارور مراجعه كننده به درمانگاه نابارورى شـهيداكبر آبادى شـهر

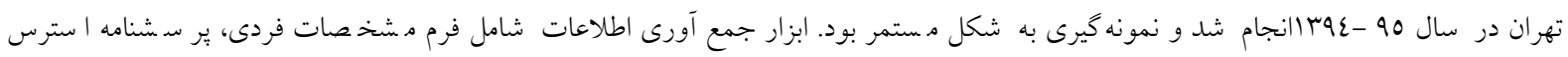

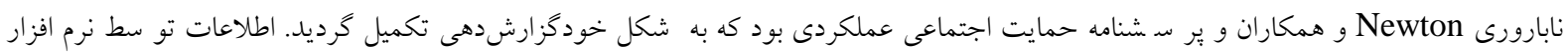
نسخه 17 و ازطريق آزمون هاى تى مستقل و كاى دو مورد تجزيه و تحليل قرار كرفتند.

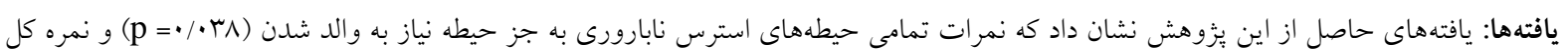

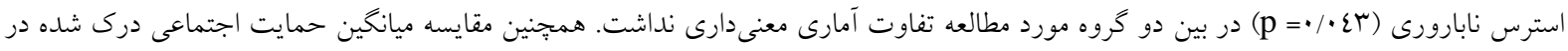

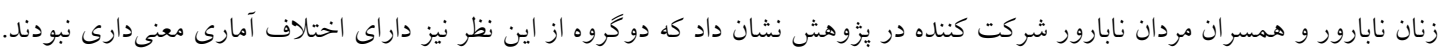

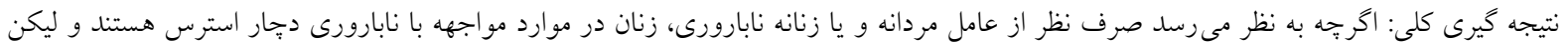

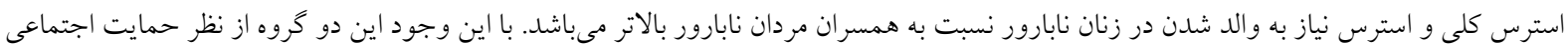
تفاوت معنى دارى ندارند.

كليد وازهها: نابارورى، حمايت اجتماعى، استرس، افسردگى، اضطراب تعارض منافع: وجود ندارد. تاريخ دريافت: 9N/N/TN

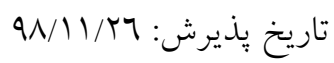

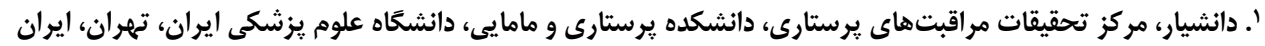

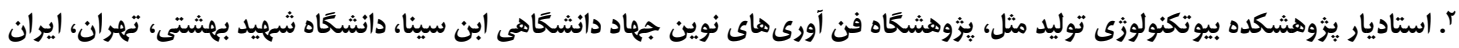

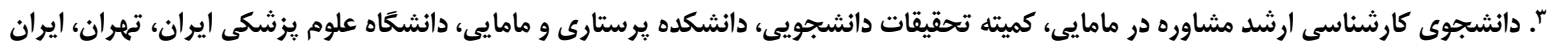
E-mail: bahar.afshar1372m@gmail.com 
صورتى كه شوهرانشان داراى سطوح بالاى استرس باشند،

$$
\text { تضعيف مىشود (r) }
$$

اكرجهه تشخيص و درمان نابارورى، بحر انى فرسايشى بوده

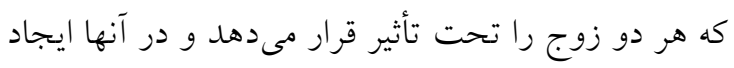

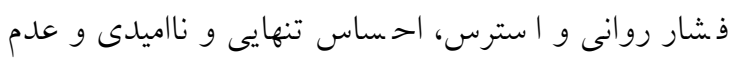

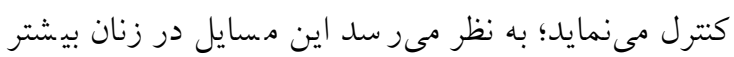

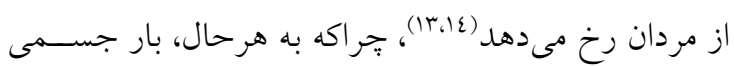
و روانى درمان هاى نابارورى و عواقب شكست احتمالى

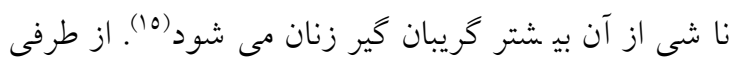
حمايتهاى اجتماعى از اين افراد مى تواند به عنوان عنصر فئر

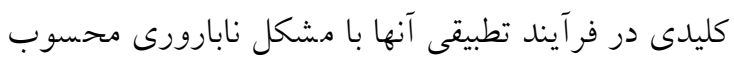

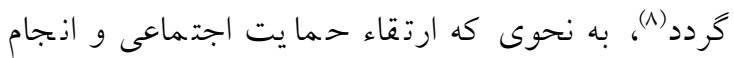

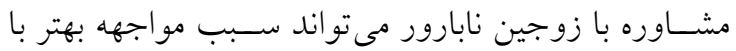

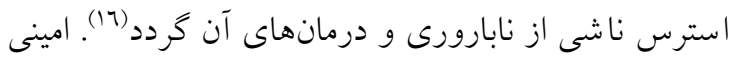

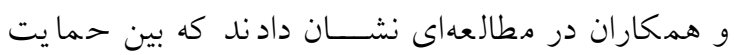

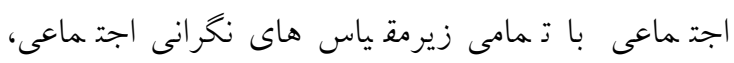

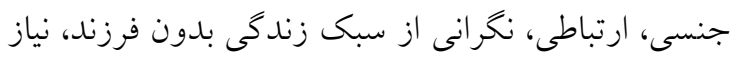

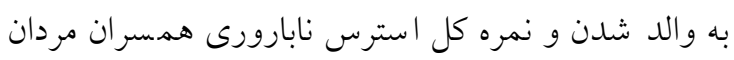

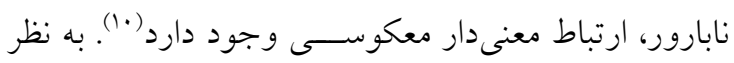

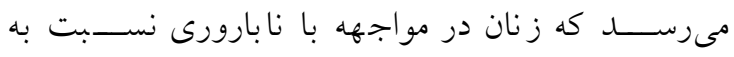
همسـرانشـان بيشتر در جسـتجوى كسـب حمايتهاى اجتماعى، فرار و اجتناب و بازنخرىهاى مثبت هـ ستند (IV).

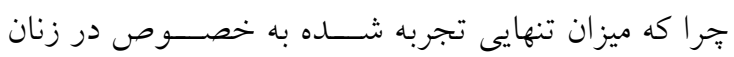

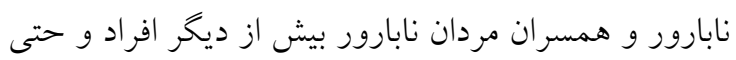
افراد مبتلا به ســرطان تخمين زده شــــه اسـتـ اين افراد

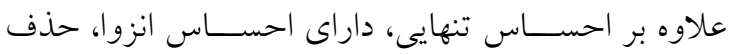

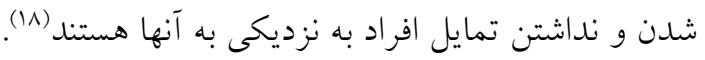

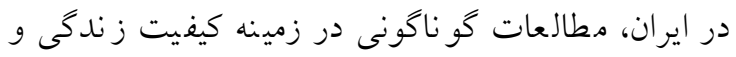
مسايل روانشناختى افراد نابارور انجام شده است اما اغلب اين مطالعات به بررسـى مســايل روانى در زنان نابارور

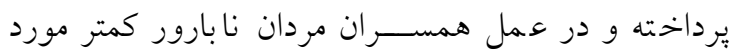

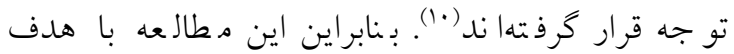
مقاي سه ا سترس نابارورى و حمايت اجتماعى درى شده لرنه در زنان نابارور و همسران مردان نابارور انجام شد.

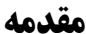
نابارورى مشـكل شـايعى اسـت كه حدود 10 - • ادرصــ زوجها را شامل مى شود (1). بر طبق آمار سازمان بهداشت مانت جهانى، در حدود •N - •7 ميليون زوج در سرا سر دنيا از نابارورى رنج مىبرند(r). در ايران، اين آمار در اسـتانهاى

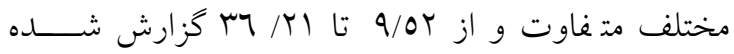
اســت (r). نابارورى به عنوان يكى بحران در زندگى افراد

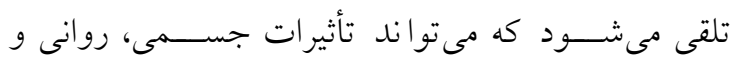

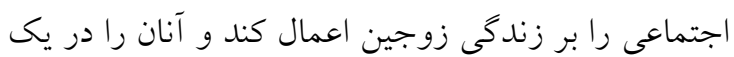
موقعيت تنش زا قرار دهد (ع). نحئ.

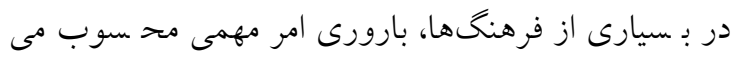
شود و تمايل به دا شتن فرزند، يكى از ا صلىترين انخيزه هاى انسانى است و نداشتن فرزند، زوجين را در موقعيتى

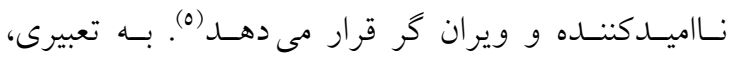
نابارورى مانند ضـــايعهاى مختل كننده در زندكى زوجين عمل كرده و آنها را به سـمت اسـترس بيش مي برد (7)، به نحوى كه در مـطالعهاى ز نان، نابارورى را تنشزاترين

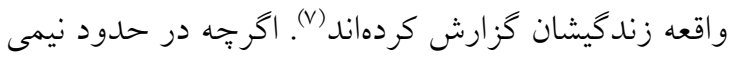
از موارد، نابارورى علت مردانه دارد(^)، ولى اين مســـأله

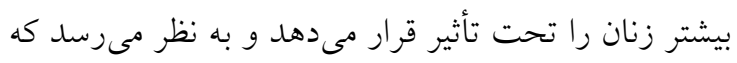
نابارورى ابعاد بيشــترى از زندگى زنان نابارور را تحت

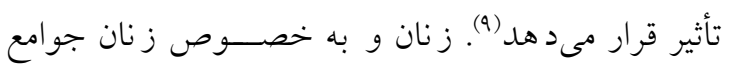
شرقى و از جمله زنان ايرانى كه در فرهنخ آنها، دا شتن فرزند و بارورى ذسبت به ديخر جوامع، بـسيار با ارزشتر محســوب مىشـود حتى زمانى كه زن بارور بوده و علت نابارورى مردانه باشد، به طور مشابهى استرس نابارورى را تجربه مى كنند؛ جرا كه در نهايت، صــرف نظر از عامل نابارورى، نتيجه، نداشـتن فرزند اســت (•). اســتيخما يا برجســبـ اجتماعى كه زنان نابارور دريافت مىكنند، در صــورتى كه در شـــرايط كاهش حمايت خانو اده باشــند،

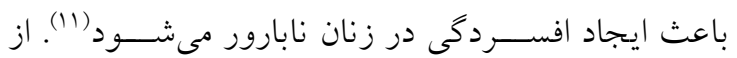

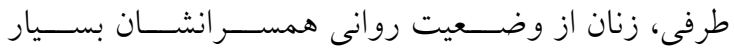

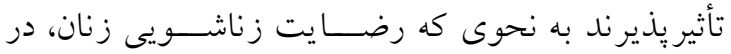


سئو ال) با دامنه نمرات •7-·• (1، سبك زندكى بدون فرزند

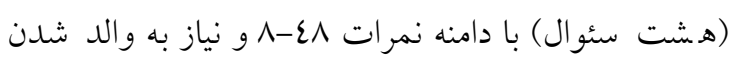

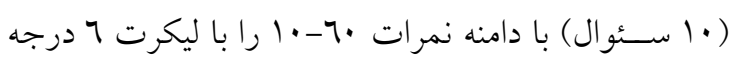

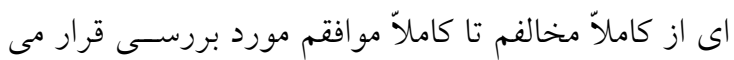

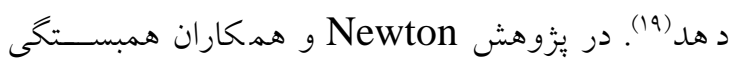

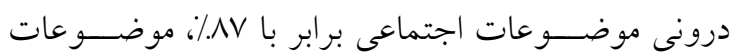
جنسى (IVV)

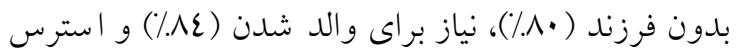

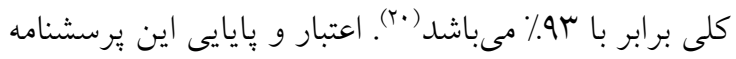

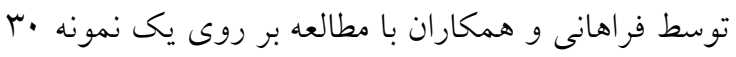

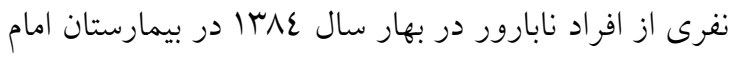
خمينى صورت گرفته است. در اين مطالعه ضريب آلفاى

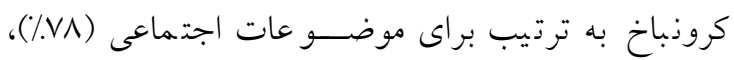

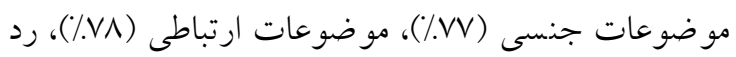

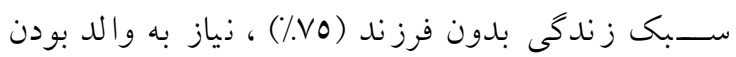

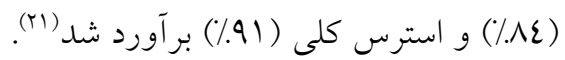

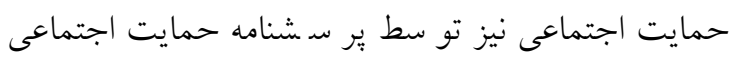

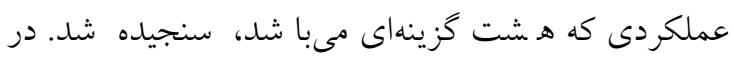

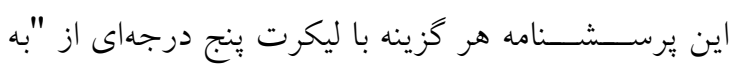

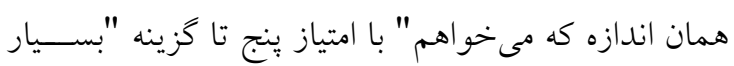

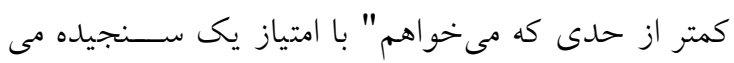

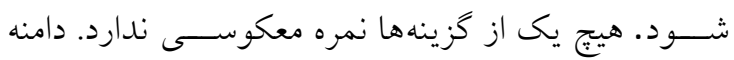

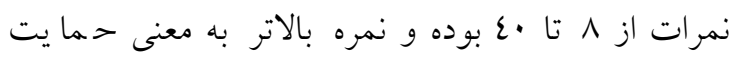

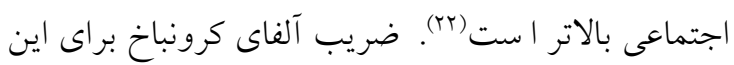

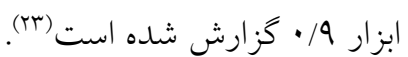

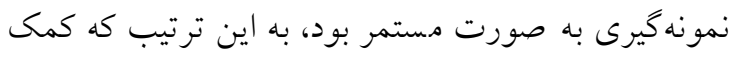

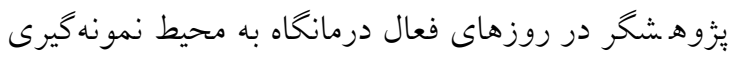
مراجعه كرده و نمو نه كيرى تا تكميل حجم نمو نه ادامه

معيار هاى ورود به مطالعه شــامل مليت ايرانى زوجين،

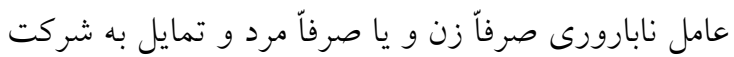

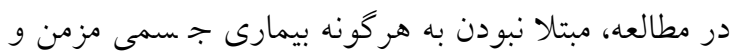
يا بيمارى روانى شـناخته شــده، مصـرف نكردن داروهاى

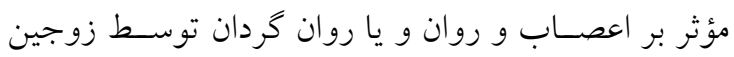

\section{روش بروسى}

اين م. رطالعه مقطعى بر روى مرائ مراجعه كذند كان به مركز

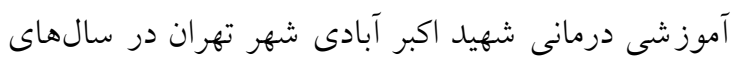

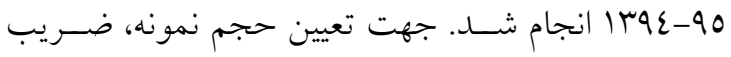

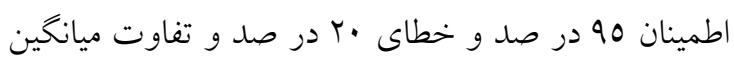

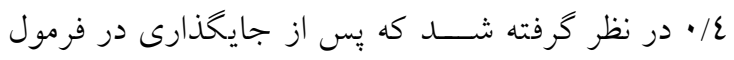

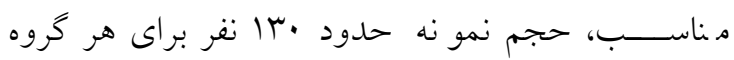

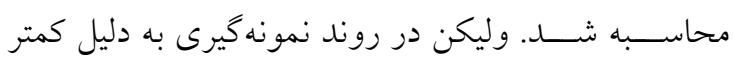

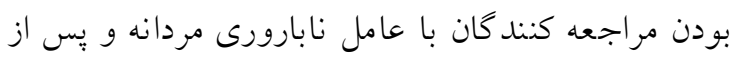

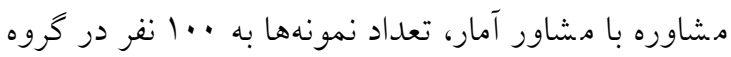

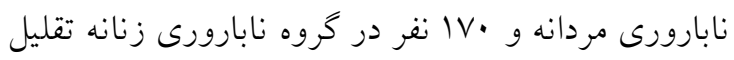
يا فت. در ذها يت تعدادى از نمو نه ها به دليل عدم بـام ياسخحويى به بيش از •ا در صد سئوالات، از نمونه كيرى

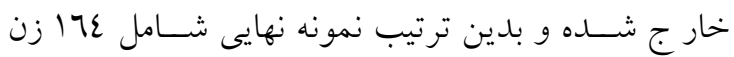
نابارور و سه نفر از همسران مردان نابارور شد. اين طرح، به شماره 16739-28-01-91 و با كد اخلاق IR.IUMS.REC.1391.16739 مصــوب دانشــاه علوم يز شكى ايران مىباشد. يُزوهشخر و كمك يزوهشخر

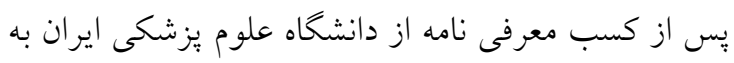

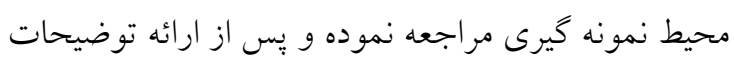

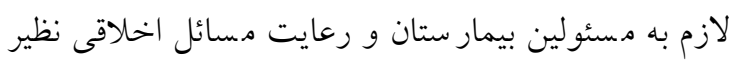

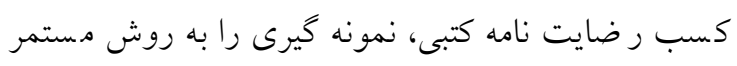

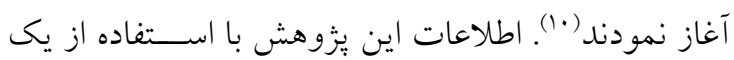
ابزار سه قسمتى جمع آورى شد. قسمت اول ابزار، شامل مشخصات فردى و بارورى افراد شركت كننده شامل سن،

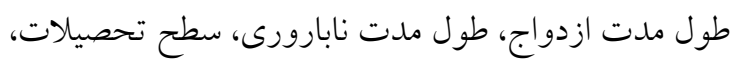
وضعيت اشتغال، وضعيت اقتصادى و علت نابارورى بود.

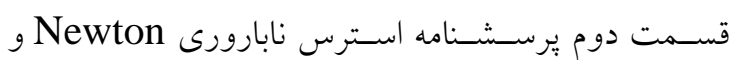

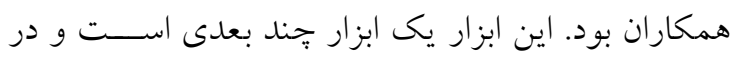

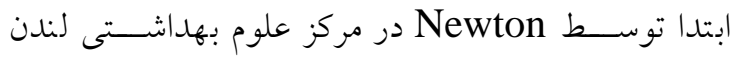
تدوين شده است. ير سشنامه استرس نابارورى شامل 27

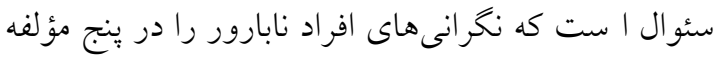

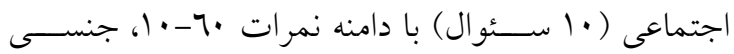

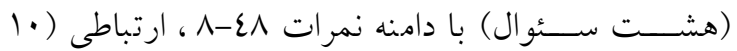




\section{يافتهها}

يافتهاى حاصـل از اينها يزّوهش نشــان داد كه دو گروه

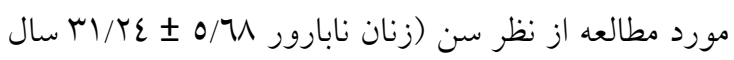

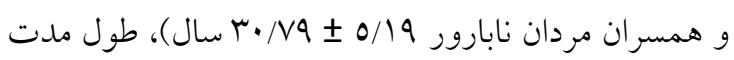

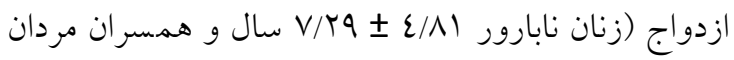

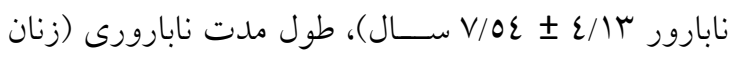

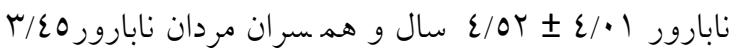

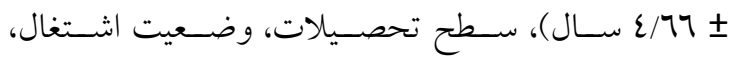
وضسعيت اقتصـادى تفاوت معنى دارى نداشـتند. همجنين T/T/ در صد زنان نابارور و VV/T در صد هم سران مردان

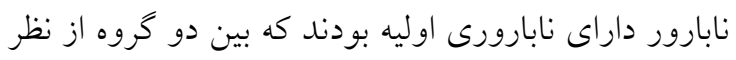
اين متغير نيز تفاوت معنىدارى وجود نداشــت. توزيع فراوانى برخى مشــصــات فردى زنان شـركت كننده در مطالعه در جدول شماره ا نمايش داده شده است.
بود. افراد در هر مرحلهاى از مطالعه مىتوانسـتند از ادامه شركت انصراف داده و از مطالعه خارج شوند.

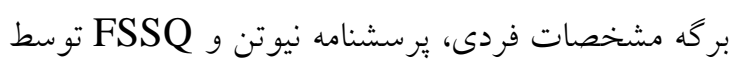

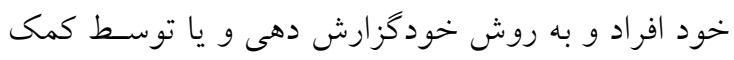

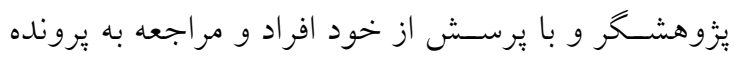

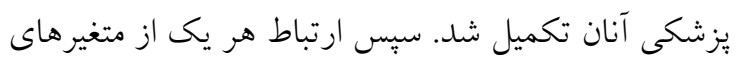
مورد مطالعه بر طبق اهداف و ســئوالات يزوهش، مورد سـنجش و بررسى قرار گرفت و دادهها توسـط نرم افزار

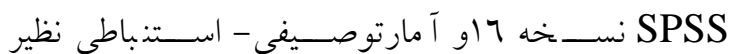
آزمونهاى تى مستقل و كاى دو مورد تجزيه وتحليل قرار

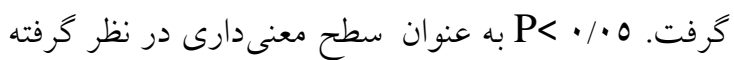

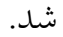

جدول شماره ا: توزيع فراوانى مشخصات فردى زنان شركت كننده در دو تَروه مورد مطالعه

\begin{tabular}{|c|c|c|c|c|c|c|}
\hline \multirow[t]{2}{*}{ نتايج آزمون } & \multicolumn{2}{|c|}{ همسران مردان نابارور } & \multicolumn{2}{|c|}{ زنان نابارور } & \multirow{2}{*}{\multicolumn{2}{|c|}{ متغير }} \\
\hline & درصد & فراوانى & درصد & فراوانى & & \\
\hline$X^{2}=1 / 1 \varepsilon \varepsilon$ & OTN & $\varepsilon \wedge$ & $01 / r$ & $\wedge r$ & كمتر از •rr & \\
\hline$d f=r$ & $\varepsilon 1 / \wedge$ & r & $r q / 0$ & $7 \varepsilon$ & $r \cdot-\varepsilon \cdot$ & سن (سال) \\
\hline $\mathrm{p}=\cdot / 07 \varepsilon$ & $0 / 0$ & 0 & $9 / \pi$ & 10 & بيشتر از •ع & \\
\hline$X^{2}=0 / r \Lambda \uparrow$ & $10 / 1$ & $1 \varepsilon$ & $1 \varepsilon / V$ & $r \varepsilon$ & ابتدايى و راهنمايى & \\
\hline $\mathrm{df}=\mathrm{v}$ & $r V / r$ & $\varepsilon \varepsilon$ & $\varepsilon 1 / r$ & TV & دبيرستان و دييلم & سطح تحصيلات \\
\hline \multirow[t]{2}{*}{$\mathrm{p}=\cdot / 71 \%$} & $M / / r$ & rq & $r_{N / \tau}$ & $\pi$ & فوق دييلم و ليسانس & \\
\hline & $7 / 0$ & 7 & $0 / 0$ & 9 & فوق ليسانس و دكترا & \\
\hline$X^{2}=I / N \mid Y$ & $\Lambda \cdot / 2$ & v. & $V N / 9$ & ir. & خانه دار & \\
\hline $\begin{array}{c}d f=r \\
p=\cdot / \varepsilon \cdot \varepsilon\end{array}$ & $19 / 7$ & iv & $r M / 1$ & rr & شاغل & وضعيت اشتغال \\
\hline$X^{2}=1 / r \cdot r$ & $9 / r$ & $\wedge$ & $O N$ & 9 & ن نامطلوب & \\
\hline$d f=r$ & $V \varepsilon / \varepsilon$ & $7 \varepsilon$ & $v q / 7$ & 1ro & نسبتا مطلوب & وضعيت اقتصادى \\
\hline $\mathrm{p}=\cdot / 0 \mathrm{r}$ & $17 / r$ & $1 \varepsilon$ & $1 \varepsilon / 7$ & rr & مطلوب & \\
\hline
\end{tabular}


معنى دارى نداشـتهاند. اين نتايج نشـان مى دهد كه ميانخين

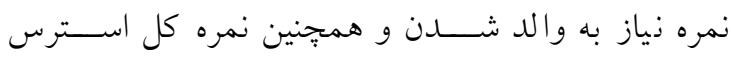
نابارورى در زنان نابارور بي شتر از هم سر ان مردان نابارور

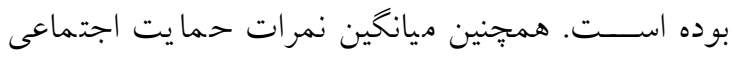

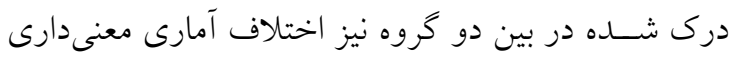
نشان نداد.
جدول شــماره Y به مقايســـه ميانخين نمرات كلى و

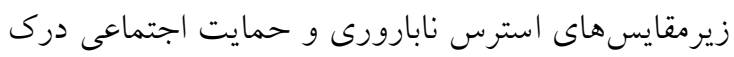

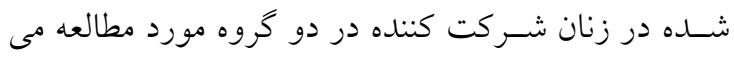

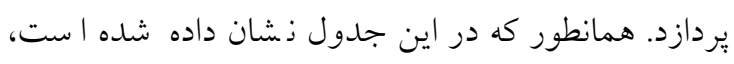

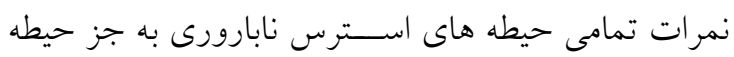

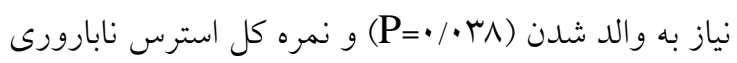

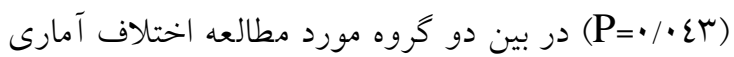

جدول شماره ז: مقايسه ميانكين نمرات كلى و زيرمقايس هاى استرس نابارورى و حمايت اجتماعى درك شده در زنان شركت كننده در دو ترووه مورد مطالعه

\begin{tabular}{|c|c|c|c|}
\hline t & 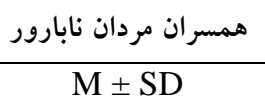 & زنان نابارور & كروه \\
\hline $\begin{array}{l}\mathrm{t}=\cdot / 971 \\
\mathrm{df}=r 00 \\
\mathrm{p}=\cdot \pi r \varepsilon\end{array}$ & $01 / \pi \% \pm 17 / 19$ & $0 r / 00 \pm 1 / / \cdot 1$ & 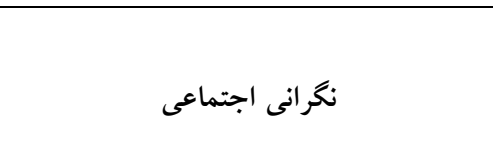 \\
\hline $\begin{array}{c}\mathrm{Z}=-1 / 071 \\
\mathrm{df}=r 00 \\
\mathrm{p}=\cdot / 11 \wedge\end{array}$ & $\{N / \cdot 0 \pm|V / \varepsilon|$ & $01 / 0 . \pm 19 / V \varepsilon$ & ن نكرانى جنسى \\
\hline $\begin{array}{c}\mathrm{Z}=-1 / \mathrm{V} 99 \\
\mathrm{df}=r 00 \\
\mathrm{p}=\cdot / \cdot \mathrm{Vr}\end{array}$ & $\varepsilon 1 / 70 \pm 1 T / N T$ & $\varepsilon 0 / r \cdot \pm 10 / \Gamma \varepsilon$ & 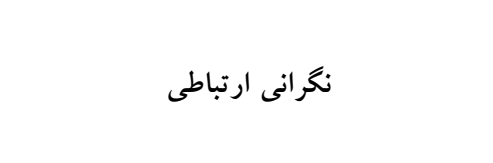 \\
\hline $\begin{array}{c}\mathrm{Z}=-\cdot / r 00 \\
\mathrm{df}=r 00 \\
\mathrm{p}=\cdot / \mathrm{\vee} 99\end{array}$ & $0 \varepsilon / N 1 \pm 10 / \pi 9$ & $07 / \Lambda \cdot \pm 1 \varepsilon / 17$ & نخرانى از سبك زندگى بدون فرزند \\
\hline $\begin{array}{l}\mathrm{t}=r / \cdot M \Lambda \\
\mathrm{df}=r 00 \\
\mathrm{p}=\cdot / \cdot r \Lambda\end{array}$ & $79 / \pi v \pm 10 / 09$ & $V \mu / \nu \cdot \pm \mid r / .0$ & نياز به والد شدن \\
\hline $\begin{array}{l}\mathrm{t}=r / \cdot r \mathrm{r} \\
\mathrm{df}=r 00 \\
\mathrm{p}=\cdot / \cdot \varepsilon r\end{array}$ & $\Delta r / \cdot|V| \pm \mid r / \cdot \wedge$ & $07 / r \cdot \pm 11 / N 7$ & نمره كل استرس نابارورى \\
\hline $\begin{array}{c}\mathrm{Z}=-\cdot / r 07 \\
\mathrm{df}=r 00 \\
\mathrm{p}=\cdot / \mathrm{A} \wedge\end{array}$ & $r / 9 r \pm \cdot / V \Lambda$ & $r / 9 V \pm \cdot / V r$ & حمايت اجتماعى درك شده \\
\hline
\end{tabular}

همســـران مردان نابارور اخر جهه در حيطه هاى نخرانى بحث و نتيجه كيرى

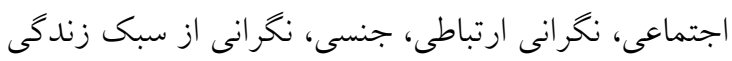
در نهايت، مقايسـهـ ميانخين نمر ات كلى و زيرمقايس هاى

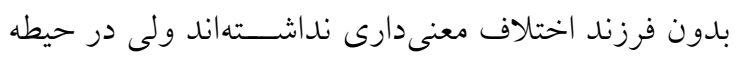
استرس نابارورى در زنان نابارور و همسر ان مردان نابارور

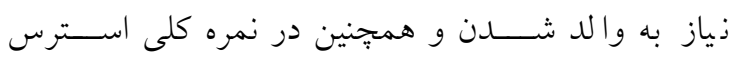
شـــركت كننده در يزوهش نشــان داد كه زنان نابارور و 
هايى نظير اضطراب، استرس، افسردكى و اندوه را ذشان

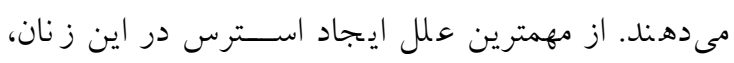

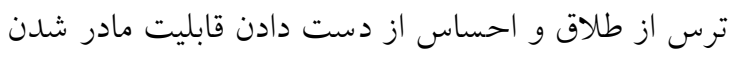

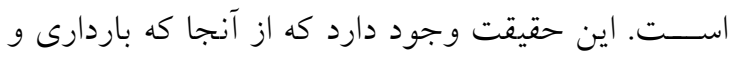
نقش مادرى مختص زنان است، توقعات اجتماعى از زنان

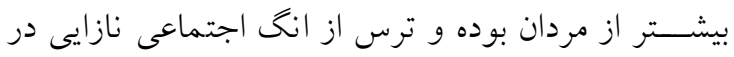

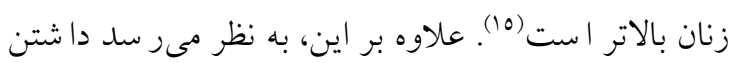

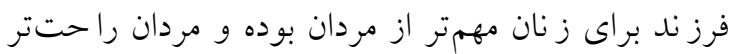

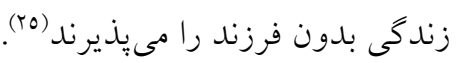

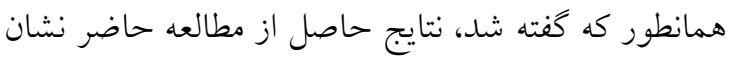
دهنده وجود نداشـتن اختلاف معنى دار بين دو كروه زنان شــر كت كننده در بزوهش در نمرات تمامى حيطه هاى

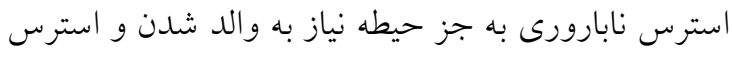
كلى نابارورى بود. اين بدين معنى اســت كه وقتى زنان

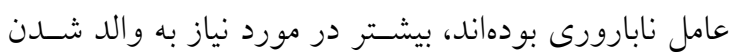

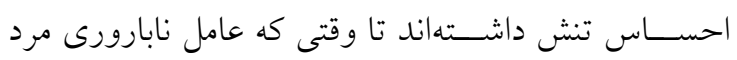

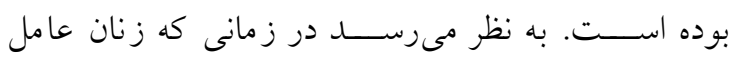

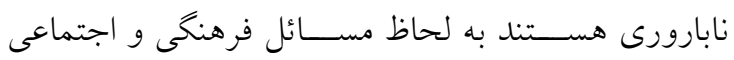

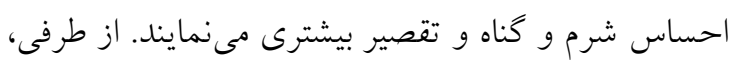

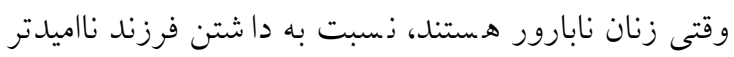

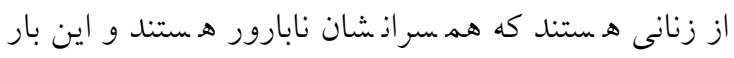

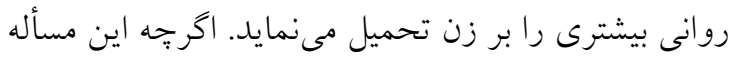

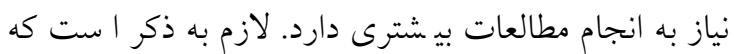

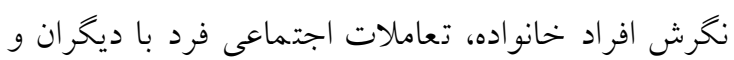
انتظارات جامعه نيز مى تواند از مهمترين بيش بينى كننده هاى استرس نابارورى باشد (r).

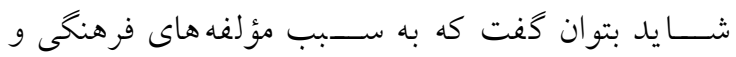

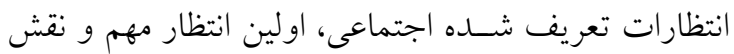
يِيش بينى شـــده براى زنان و مردانى كه ازدواج مى كنند، بجهدار شدن ا ست به نحوى كه در فرهنگ عاميانه ايرانى

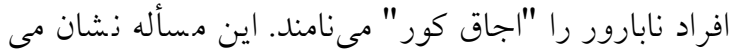
دهد كه در فرهنگ ايرانى ندا شتن فرزند به معنى ندا شتن

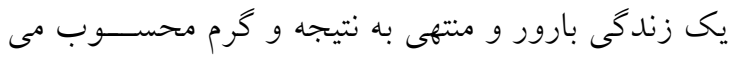

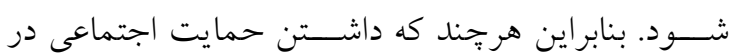

نابارورى، اين اختلاف معنىدار بوده و زنان نابارور ذسبت

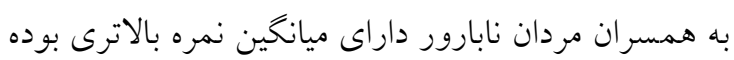

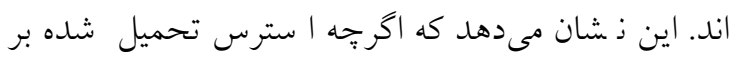

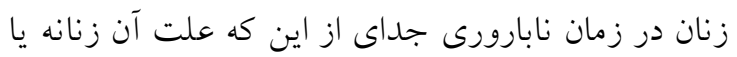

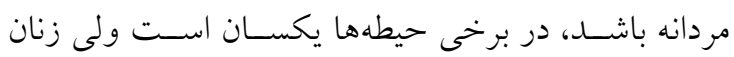

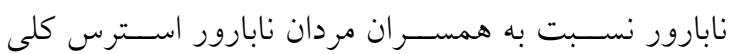

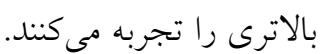

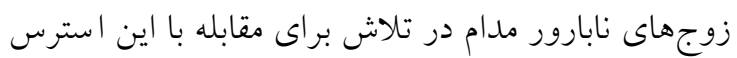

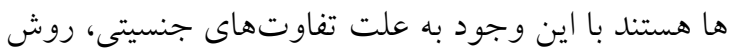

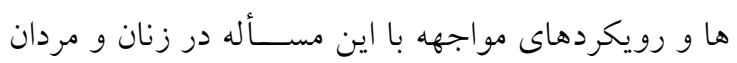

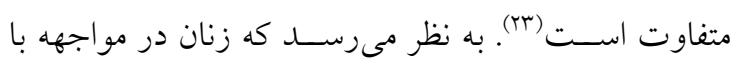
نابارورى نسبت به همسر انشان بيشتر در جستجوى كسب

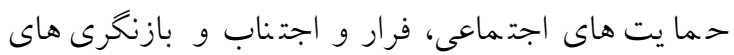
مثبت هستند. با اين وجود شباهتهاى رويكردهاى مردان

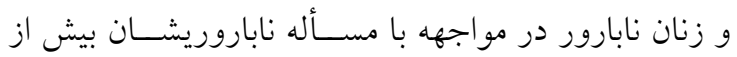

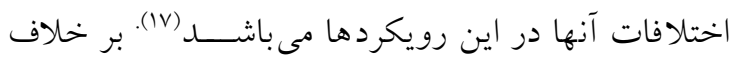
مطالعه Wiweko و همكاران در اندونزى كه در مطالعه

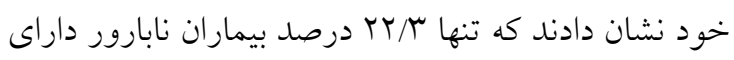
استرس نابارورى مىبا شند، در مطالعه حاضر تمامى زنان

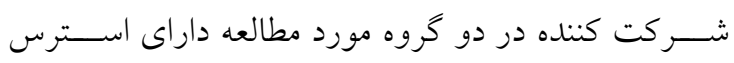

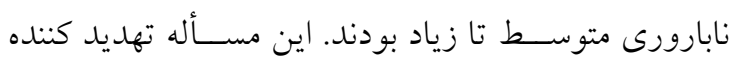

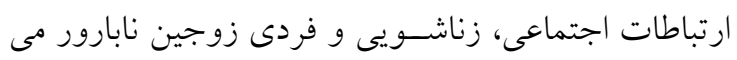

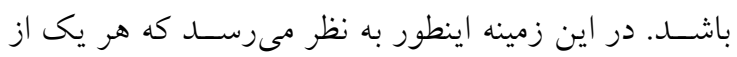

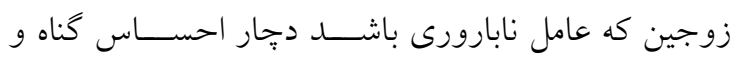
خود سرزنشى بيشترى شده و همين مسأله سبب افزايش

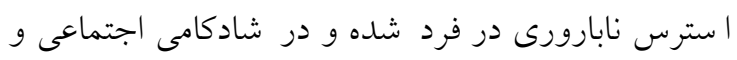

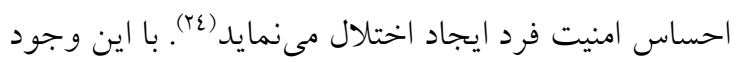
مطالعه حاضــر نشــان داد كه همســــان مردان نابارور در بسيارى از حيطهها به اندازه زنان نابارور دجار استرس مى في

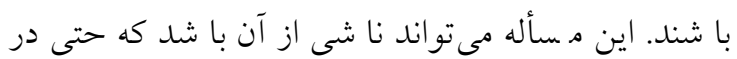

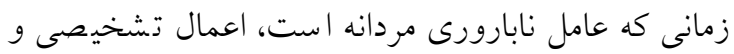

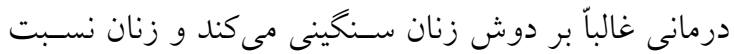

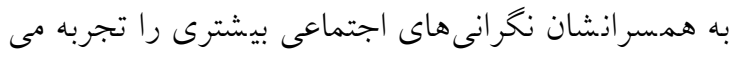

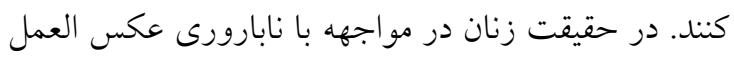


كمترى دريافت نمايند. از طرفى، ينهان كردن نابارورى از ديخران ممكن است سبب شود كه نزديكان فرد را بيشتر

$$
\text { در فشار فرزندآورى قرار دهند (^^). }
$$

دسترسى نداشتن به همسران مردان نابارور به دليل مراجعه

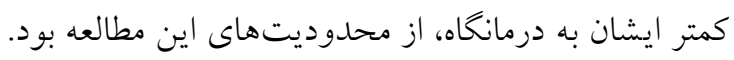
با توجه به اين كه اين مطالعه در يك مركز و با مراجعين

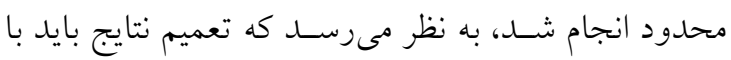

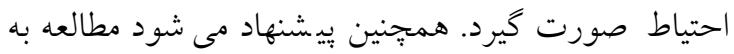

$$
\text { صورت קند مركزى انجام شود. }
$$
اين مطالعه نشـان داد كه استرس نابارورى در زنان ايرانى

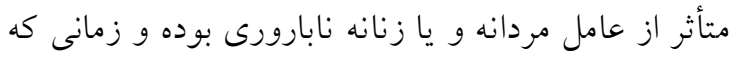

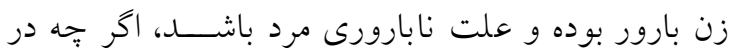
نهايت نتيجه، ندا شتن فرزند براى هر دو زوج است، زنان اسـترس كمترى را نسـبت به زنان نابارور تجربه مى كنند.

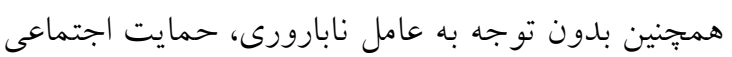
در هر دو گروه به يك اندازه مىباشد.

تعارض منافع: هيج گونه تعارض منافع تو سط نويسندگان

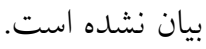

\section{تقدير و تشكر}

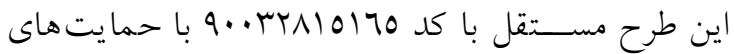
مالى دانشـحاه علوم بزشـكـى ايران انجام شــــه اســت.

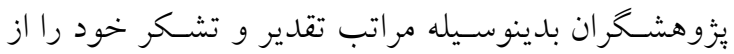

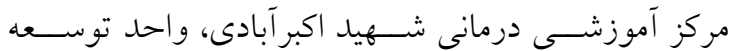
تحقيقات بالينى بيمار ستان شهيد اكبرآبادى و جناب آقاى

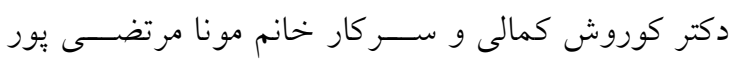

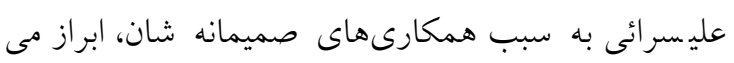

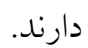

كاهش اسـترسهاى فرد مؤثر اسـت اما احتمالاً در خلوت

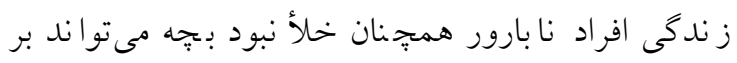

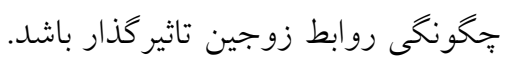

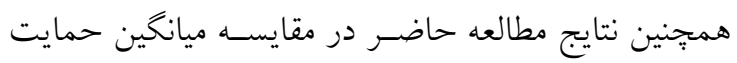
اجتماعى درك شــــه در زنان نابارور و همســــــان مردان

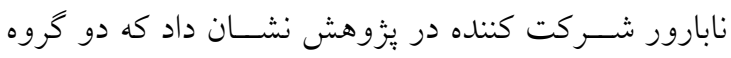

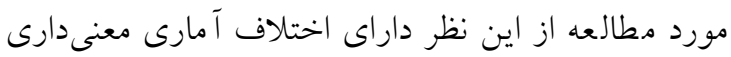
نبودهاند. اين بدان معنى است كه همسران مردان نابارور به

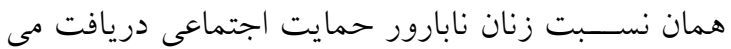
كردهاند كه اين ميزان، از ميانخين نمره حمايت اجتماعى بماني مورد انتظار از ابزار، كمتر بوده اسـت. اكر جهه زنان بيشـتر

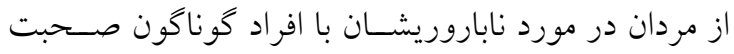

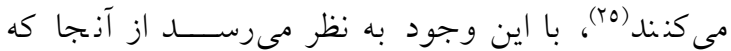

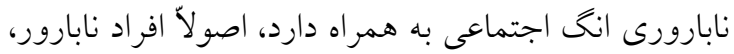

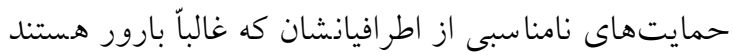

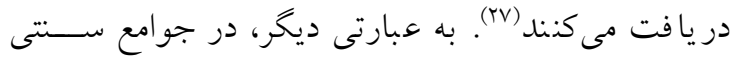

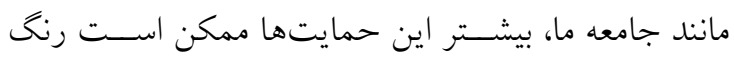

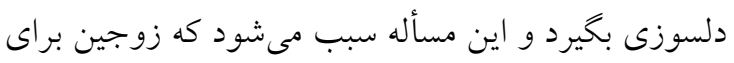

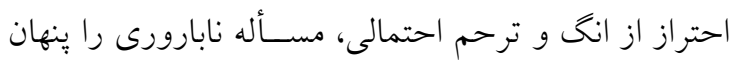

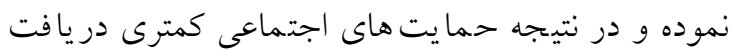

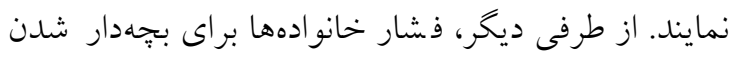

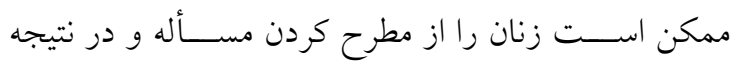

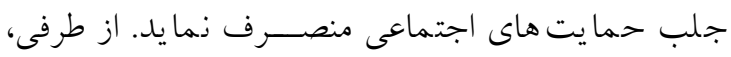

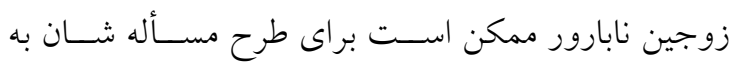

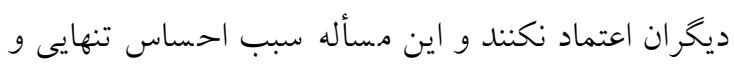
انزواى اجتماعى و كاهش حمايتهاى اجتماعى كردد. از

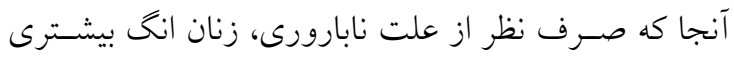
را تحمل مى كنند، اين ينهان كارى از طرف زنان بيشــر

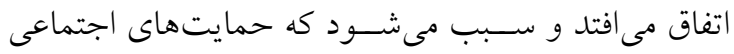

\section{References}


1. Curtis M. Inconceivable: how barriers to infertility treatment for low-income women amount to reproductive oppression. Geo. J. on Poverty L. \& Pol'y. 2017;25:323.

2. Ombelet W, Cooke I, Dyer S, Serour G, Devroey P. Infertility and the provision of infertility medical services in developing countries. Human reproduction update. 2008;14(6):605-21.

3. Akhondi MM, Kamali K, Ranjbar F, Shirzad M, Shafeghati S, Ardakani ZB, Goodjani A, Parsaeian M, Mohammad K. Prevalence of primary infertility in Iran in 2010. Iranian journal of public health. 2013;42(12):1398. [Persian]

4. Vaghar MI. An investigation into the effects of psychological consultation on the sense of satisfaction of the infertile women referring to the infertility centers of Tabriz. Journal of Family Medicine and Primary Care. 2019;8(3):1170. [Persian]

5. Alami ML, Amanati L, Shekarabi S, Haghani H, Ramezanzade F. Quality of life in infertile women and related factors. Iran Journal of Nursing. 2008;21(56):27-35. [Persian]

6. Donkor ES, Sandall J. The impact of perceived stigma and mediating social factors on infertilityrelated stress among women seeking infertility treatment in Southern Ghana. Social science \& medicine. 2007;65(8):1683-94.

7. Peterson BD, Newton CR, Rosen KH, Skaggs GE. Gender differences in how men and women who are referred for IVF cope with infertility stress. Human Reproduction. 2006;21(9):2443-9.

8. Kobori Y. Home testing for male factor infertility: a review of current options. Fertility and Sterility. 2019;111(5):864-70.

9. Fahami F, Hoseini Quchani S, Ehsanpour S, Zargham A. Women's lived experiences of female infertility. The Iranian Journal of Obstetrics, Gynecology and Infertility. 2010;13(4):45-53. [Persian]

10. Amini L, Ghorbani B, Sadeghi AvvalShahr H, Raoofi Z, Mortezapour Alisaraie M. The Relationship Between Percieved Social Support and Infertility Stress in Wives of Infertile Men. Iran Journal of Nursing. 2018;31(111):31-9. [Persian]

11. Ezzati A, Nouri R, Hasani J. Structural relationship model between social support, coping strategies, stigma and depression in infertile women in Tehran, Iran, 2010. The Iranian Journal of Obstetrics, Gynecology and Infertility. 2013;16(45):20-8. [Persian]

12. Maroufizadeh S, Hosseini M, Foroushani AR, Omani-Samani R, Amini P. The relationship between perceived stress and marital satisfaction in couples with infertility: actor-partner interdependence model. International journal of fertility \& sterility. 2019;13(1):66.

13. Patel A, Sharma PS, Narayan P, Binu VS, Dinesh N, Pai PJ. Prevalence and predictors of infertility-specific stress in women diagnosed with primary infertility: A clinic-based study. Journal of human reproductive sciences. 2016;9(1):28.

14. Agostini F, Monti F, De Pascalis L, Paterlini M, La Sala GB, Blickstein I. Psychosocial support for infertile couples during assisted reproductive technology treatment. Fertility and sterility. 2011;95(2):707-10.

15. Chehreh R, Ozgoli G, Abolmaali K, Nasiri M, Mazaheri E. Comparison of the infertility-related stress among couples and its relationship with infertility factors. Int J Women's Health Reprod Sci. 2018;7(3):313-8.

16. Sehhati SF, Mirghafourvand M, Rahimi M. Perceived stress and its social-individual predicors among infertile couples referring to infertility center of Alzahra hospital in Tabriz in 2013. 2014. [Persian]

17. Peterson BD, Newton CR, Rosen KH. Examining congruence between partners' perceived infertility-related stress and its relationship to marital adjustment and depression in infertile couples. Family process. 2003;42(1):59-70.

18. Jirka J, Schuett S, Foxall MJ. Loneliness and social support in infertile couples. J Obstet, Gynecol Neon Nurs. 1996;25(1):55-60.

19. Al-yazori MT. Relationship between infertility related Stress and Type of Coping among Infertile Males and females-Gaza Strip. Relationship between Infertility Related Stress and Type of Coping among Infertile Males and Females-Gaza Strip. 2012.

20. Lin YN. Counselling a Taiwanese woman with infertility problems. Counselling Psychology Quarterly. 2002;15(2):209-15. 
21. Pahlavani H, Malakouti K. Stressors, their coping strategies, and relation to mental health in infertile individuals. Iranian Journal of Psychiatry and Clinical Psychology. 2002 10;7(4):79-87. [Persian]

22. Broadhead WE, Gehlbach SH, De Gruy FV, Kaplan BH. The Duke-UNC Functional Social Support Questionnaire: Measurement of social support in family medicine patients. Medical care. 1988:709-23.

23. Yeylaghbigi M, Mazaheri MA, ST Neshatdoost T, Manshai GH, Talebi H. Investigating Changes in Anxiety and Emotion Among Women Under IVF-ICSI Therapy. Journal of Guilan University of Medical Sciences. 2014;23(90):32-41. [Persian]

24. Wiweko B, Anggraheni U, Elvira SD, Lubis HP. Distribution of stress level among infertility patients. Middle East Fertility Society Journal. 2017;22(2):145-8.

25. Nagórska M, Bartosiewicz A, Obrzut B, Darmochwał-Kolarz D. Gender differences in the experience of infertility concerning polish couples: preliminary research. International Journal of Environmental Research and Public Health. 2019;16(13):2337.

26. Wang JY, Li YS, Chen JD, Liang WM, Yang TC, Lee YC, Wang CW. Investigating the relationships among stressors, stress level, and mental symptoms for infertile patients: A structural equation modeling approach. PLoS One. 2015;10(10):e0140581.

27. Martins MV, Peterson BD, Almeida V, Mesquita-Guimarães J, Costa ME. Dyadic dynamics of perceived social support in couples facing infertility. Human Reproduction. 2014;29(1):83-9.

28. Slade P, O'Neill C, Simpson AJ, Lashen H. The relationship between perceived stigma, disclosure patterns, support and distress in new attendees at an infertility clinic. Human Reproduction. 2007;22(8):2309-17. 